\title{
A Sanctuary for cancer cells: Microenvironment in T-cell acute lymphoblastic leukemia survival and drug resistance
}

\author{
Filomena Di Giacomo ${ }^{1}$, Danilo Fiore ${ }^{1}$, Peter W. Kyriakides ${ }^{1}$ and Giorgio Inghirami ${ }^{1,2,3}$ \\ ${ }^{1}$ Department of Pathology and Laboratory Medicine, Weill Cornell Medicine, New York, NY, USA \\ ${ }^{2}$ Department of Molecular Biotechnology and Health Science and Center for Experimental Research and Medical Studies (CeRMS), University of Torino, Torino, \\ 10126 Italy \\ ${ }^{3}$ Department of Pathology, and NYU Cancer Center, New York University School of Medicine, New York, NY, 10016 USA
}

\begin{abstract}
T-cell acute lymphoblastic leukemia (T-ALL) is a heterogeneous malignancy associated with a high risk of treatment failure. Efforts to improve outcomes have focused on underlying genetic defects. However, strong evidence suggests that leukemic cells prime a maladapted niche that in turn provides signals capable of sustaining the dormancy of leukemia initiating cells and protects them from toxic chemotherapeutic agents. Here, we aim to describe how key components of the bone marrow microenvironment are essential for leukemia initiation and progression. Although many mechanisms have been recently discovered, further studies are required to fully dissect the molecular mechanisms governing the bidirectional interactions between tumor and host cells. We predict that these new discoveries will pave the way for the implementation of novel therapeutic strategies and will eventually lead to the eradication of the drug-resistant cells, substantially and ultimately enhancing cure rates for T-ALL patients.
\end{abstract}

\section{Introduction}

T-cell acute lymphoblastic leukemia (T-ALL) is an aggressive and highly heterogeneous group of neoplasms, originated from T-cell progenitors. Despite intensive chemotherapy and stem cell transplantation based therapies, most T-ALL patients experience recurrences within 2 years after diagnosis with very dismal survival perspectives [1,2]. Although cure rates have improved to approximately $75 \%$ in children and $50 \%$ in adults, poor prognosis and high disease burden remain for relapsed/refractory subsets [1]. Recent efforts have focused on unearthing the genomic background associated with naïve and refractory/relapse phenotypes, which will lead to the discovery of driving defects promoting tumor progression. The most prominent cell-intrinsic aberrations in T-cell leukemia/lymphoma include activating mutations of Notch, deletion of tumor suppressor genes and translocations with consequent aberrant expression of transcription factor oncogenes $[1,3]$. Furthermore, a high incidence of overlapping mutations in the JAK/STAT as well as PI3K/Akt/mTOR pathways was frequently found in refractory/relapsed patients [4]. These latter data correspond with the tumorigenic role of these lesions and their association with poor clinical outcome makes them valauble clinical biomarkers.

Besides these pathogenic events, increasing evidence suggests that host-mediated pro-tumorigenic signals play a critical role as well. Indeed, the marrow microenvironment acts as sanctuary for leukemic cells, promoting their survival/dormancy and protecting them from chemotherapeutic stress, thus fostering tumor refractory or relapsed phenotypes [5,6]. Recent studies have argued that rare stem-like leukemic cells, capable of recreating the entire tumor, are responsible not only for T-ALL initiation but also for propagation [7]. These rare "leukemia initiating cells" (LICs) share common features with normal hematopoietic stem cells (HSCs), such as multi-potency, dormancy and self-renewal $[8,9]$. This implies that leukemia stem cell-like cells have features that make them less responsive to therapy and can lead to cancer relapse. Therefore, elucidating the molecular and cellular properties that promote this phenotype and thus overcoming chemoresistance remains an unmet medical need.

In this review we discuss the extrinsic factors that are known to influence the survival of leukemia initiating cells.

\section{HSC niche: a peaceful community}

Strong evidence suggests that the mechanisms that define the relationship between healthy HSCs and microenvironment closely mimic those adopted by leukemic cells to escape chemotherapy.

Normal hematopoietic cells are organized in a hierarchy headed by a pool of quiescent and pluripotent stem cells bearing self-renewal capacity. By dividing and differentiating committed progenitors, they can generate mature blood cells $[10,11]$. It is evident that normal hematopoiesis requires multiple coordinated mechanisms. Two specialized regions of the BM microenvironment - the osteoblastic niche and the vascular niche - work in concert to provide distinct signals in the form of secreted factors and cell surface molecules for HSC maintenance and regulation of normal hematopoiesis [12]. The osteoblastic niche, comprised of osteoblasts, nerve cells and specialized macrophages, contributes to the maintenance of stem cell dormancy

Correspondence to: Filomena Di Giacomo, Department of Pathology and Laboratory Medicine, Weill Cornell Medicine, New York, NY, USA; E-mail: fid2002@med.cornell.edu

Key words: T-ALL, microenvironment, leukemic niche

Received: April 14, 2017; Accepted: May 15, 2017; Published: May 17, 2017 
over the long-term [13-15]. Adhesion molecules expressed by both stem cells and stromal cells work by regulating the bidirectional network and governing both HSCs dormancy and cell renewal/proliferation. These include N-cadherin, CD44 and VLA4 [16]. VLA-4 expressed by HSCs interacts with VCAM-1 on osteoblasts promoting homing and retention of HSCs within the niche [17,18]. Angiopoietin-1 secreted by osteoblasts interacts with Tie-2, a tyrosine kinase receptor on the surface of HSCs cells, leading to upregulation of $\mathrm{N}$-cadherin expression and consequently enhancing HSC-osteoblast adhesion and promoting the quiescence of HSCs [19]. Additionally, osteoblasts negatively regulate the number of HSCs in the bone marrow through the secretion of osteopontin, resulting in the inhibition of proliferation and induction of apoptosis of HSCs [20,21]. Conversely, myc expression represses $\mathrm{N}$-cadherin, inducing exit from the niche and HSC cycling [22]. The ligand jagged-1, secreted by osteoblasts, also binds to Notch and fires a signaling cascade in the HSCs, promoting self-renewal and clonal expansion[13].

Glial non-myelinated Shwann cells of the sympathetic nerves provide an additional layer of regulation contributing to the endosteal niche. These cells are in contact with a substantial number of HSCs and regulate their dormant state through transforming growth factor-beta (TGF-b)/Smad signaling [23].

At the same time, the components of the vascular niche, such as endothelial cells (EC), mesenchymal stromal cells (MSC) and megakaryocytes (Meg) support HSC maintenance, proliferation, differentiation and mobilization [14,24]. Stromal cell-derived factor-1 SDF1 (also called CXCL12) is a critical factor in homing, retention and mobilization of HSCs. It is mainly secreted by endothelial cells and in part by osteoblasts during homeostasis or tissue injuries [25]. CXCL12 is a homeostatic chemokine that binds the CXCR4 receptor on the surface of HSCs, inducing homing, chemotaxin and adhesion of HSCs. CXCL12 also leads to the activation of VLA-4 on HSCs, promoting the VLA-4/VCAM-1 signaling pathway and potentiating HSC adhesion to the endothelial cells followed by their trans-endothelial migration [26]. Growth factors, such as the Granulocyte colony-stimulating factor (G-CSF) decrease the levels of CXCL12 in the marrow and increase the expression of CXCR4 on the HSCs surface. As consequence, HSCs are free to mobilize in the peripheral blood [27,28]. Additionally, G-CSF induces the secretion of proteolytic enzymes such as matrix metalloproteinases (MMPs) that disrupts the cell-cell anchorages between HSCs and stromal cells, promoting mobilization of HSCs [29]. Lastly, endothelial cells also express Notch and c-Kit ligands as well as a specific set of angiocrine factors (FGF, Ang-1, IGFBP2), promoting HSC self-renewal and proliferation.

\section{Leukemia march to the marrow: a new landlord}

There is ample evidence supporting the hypothesis that the same extrinsic factors provided by the bone marrow niche responsible for maintaining the quiescence of HSCs may also facilitate LICs survival. LICs themselves alter the architecture of the BM microenvironment, triggering a maladapted niche that supports neoplastic phenotypes and progression [30,31]. Emerging evidence indicate that leukemic cells can "educate" the neighboring stroma to block the interactions between normal niche and residing HSCs, paving the way for a new pathological niche. Using four-dimensional imaging, Hawkins et al. pointed out how T-ALL cells invade the bone marrow and lead to rapid remodeling of the endosteal niche, with a total loss of mature osteoblasts. Similarly, using a mouse model of Notch-driven T-ALL, Wang et al. [32] showed that leukemic cells affect the homing of healthy
HSCs, compete for the occupancy of perivascular areas and suppress the number of osteoblasts, disrupting the normal hematopoiesis. The authors demonstrated the key role of Notch pathway in these processes, since Notch blockade recovered the osteoblasts and fostered HSCs proliferation in vivo. Interestingly, Enciso et al. [33] developed a dynamic Boolean network and proposed that up-regulation of NF-kB signaling contributes to ALL progression in concomitance to normal hematopoietic failure through disruption of CXCL12/CXCR4 and VLA4/VCAM-1 axes.

\section{Leukemic niche: guilty of aiding and abetting}

The first crucial step in leukemia-stroma interaction is the homing and adhesion of LICs to protective niches. This is orchestrated by chemokines produced by the microenvironment, that interact with specific receptors on the surface of LICs inducing the production of integrin and adhesion molecules. One of these key mediators is CXCL12, known to play a critical role in hematological malignancies as well as in solid tumors. Specifically, CXCL12 regulates invasion and controls metastatic capacity. Activated CXCR4 induces migration, adhesion, survival and proliferation of leukemic cells through the activation of multiple signaling pathways, including JAK/STAT, MAPK, PI3K/Akt and PKC. Of note, the deregulation of these pathways is also known to cause drug-resistance in ALL cells $[34,35]$. Using dynamic in vivo confocal imaging Sipkins et al. [36] have recently showed that when leukemic cells are injected in mice, they selectively localize in specific areas of marrow vasculature expressing high levels of E-selectin and CXCL12. The role of E-selectin has been proven using knock-out mice in which leukemic cell homing is considerably compromised. This is also in line with the data generated by small molecules that inhibit CXCL12-CXCR4 interactions. Indeed, the treatment of mice with AMD3100 dramatically affected leukemic homing, providing direct evidence that CXCR4 is necessary for this process and for retention of cancer cells into the marrow spaces [5]. Similarly, the work of Pitt et al. [6] has showed that direct contact of T-ALL with CXCL12-producing vascular endothelial cells allows for the creation of protecting leukemic niches. Collectively, these findings strongly support the potential of CXCR4 inhibitors in the treatment of T-ALL.

Interleukins also play an important function in the interplay between tumor and stroma elements. Relapsed B-ALL and stromal cells from leukemic BM niches have been shown to express higher levels of interleukins and their receptors, as compared to the levels observed in normal samples, thereby suggesting the existence of complex autocrine/paracrine loops regulating leukemic cell functions [37]. Toward this end, in vitro experiments proved that marrow-released CXCL12 increases IL-8 production in T-ALL cells through NF-kB and c-Jun phosphorylation [38]. A recent study has demonstrated that the inhibition of IL-18 pathway in T-ALL cells is associated with a delay of leukemia progression in xenograft models [39]. Moreover, Chiaretti et al. [40] have shown, by gene expression analysis, that IL-18 is highly expressed in refractory T-ALL patients compared to responders. An other critical lymphokine is Interleukin-6 (IL-6), which appears to be a promising factor to further study the interplay between T-ALL and microenvironment. This cytokine is a strong activator of the JAK/ STAT pathway and induces cell proliferation and inhibits apoptosis via cyclins, c-myc and bcl-2. Notably, in bone marrow of ALL patients IL-6 is increased and its levels correlate with the severity of disease [41].

In addition to the cytokines, a prominent role is played also by growth factors. Triplett et al.[42] have shown that dendritic cells (DCs) from the tumor microenvironment promote T-ALL growth 
and facilitate leukemia survival in both primary thymic and metastatic tumor sites. Using gene expression profiling, they found the upregulation of both PDGFRB and IGF1R on T-ALL cells and their cognate ligands by tumor-associated DCs.

Considering the importance of Notch signaling, its role in the crosstalk with stroma has been the object of extensive investigation. Of note, the over-expression of Notch 3 ligand DLL- 4 by bone marrow vascular endothelium promoted T-ALL survival and its inhibition delayed leukemia-initiating activity in xenograft models [43,44]. In addition to T-ALL, B-ALL also shows high expression levels of both Notch 3 and 4 receptors. Their activation, controlled by DDL-1 or Jagged-1 ligands expressed by BM-mesenchimal cells, sustains primary B-ALL survival and promotes chemoresistance to hydrocortisone in co-culture experiments [45].

Moreover, several adhesion molecules have been proven to regulate the activation of intracellular signals, promoting the survival of T-ALL via BM stroma-mediated engagement. LFA-1/ICAM-1 adhesive interactions as well as VCAM-1 and E-selectine molecules are also necessary for the survival of T-ALL cell lines and patient-derived T-ALL cells on BM stroma in vitro [46]. Lastly, B-ALL of relapsed patients have been shown to express high levels of VLA-4, which interacts with VCAM-1 on the stromal cells leading to the differential expression of a battery of genes involved in PI3K/mTOR, Wnt and NFkB signaling pathways $[47,48]$.

\section{Breaking the alliance}

Clinically, T-ALL patients are most commonly treated by highdose multiagent chemotherapy protocols, frequently followed by bone marrow stem cell transplantation, once a molecular remission is achived with a curate intent. Despite the introduction of such aggressive treatments, more than $20 \%$ of children and $40 \%$ of adults unfortunately become resistant to chemotherapy and eventually relapse [1,2]. Several preclinical studies have shown some degree of efficacy for a variety of inhibitors that specifically target multiple intrinsic alterations, often in combination with lower dose of chemotherapeutic agents. Despite these novel attempts, only minimal results have been achieved and effective therapeutic protocols remain an unmet medical need.

The deregulated activation of the JAK/STAT signaling pathway has been recognized in many refractory/relapsed T-ALL cases. Unchecked PI3K/Akt signals enhance resistance to apoptosis, promoting tumor development and progression. Additionally, PTEN, that physiologically acts as a negative regulator of the pathway, is deleted and/or defective in many T-ALL patients; a phenomenon linked to the maintenance of leukemic stem cell phenotype and tumor progression. The Notch and Wnt signaling pathways are well known as key regulators of LICs self renewal activity, and are both activators of c-myc expression [49-52]. In addition, the HIF1 a pathway modulates the self-renewal activity and differentiation of both normal and leukemic cells in hypoxic conditions $[53,54]$. A subset of LICs with active Wnt signaling has proven to reside preferentially within hypoxic niches in a mouse model of Notch-driven T-ALL. In particular, HIF1 $\alpha$ upregulates the expression of $\beta$-catenin at the transcriptional level, which in turn potentiates Wnt signaling $[55,56]$. Targeting these key signaling cascades represents an attractive strategy. The $\gamma$-secretase inhibitors (GSIs), which block the proteolytic cleavage of the Notch receptors and preclude the release of activated Notch1 (ICN1) from the membrane, have been proposed as potential targeted therapy in T-ALL. Despite the promising results in preclinical in vitro and in vivo models, the effects of GSIs are transitory and the treated mice eventually undergo tumor progression followed by death.
The non-competitive and reversible agent, PF-03084014, selectively inhibits $\gamma$-secretase and has been proven to lead a full hematological recovery in T-ALL patients with acceptable toxicity [57]. Similar results have been achieved in a single patient treated with GSI BMS906024 [58].

Interestingly, the association of GSI with the mTOR inhibitor rapamycin has proven to be effective in increasing apoptosis, decreasing tumor burden and prolonging the overall survival in leukemic mice [59]. Similarly, GSI and PI3K or c-myc inhibitors synergistically decrease human T-ALL in vitro $[60,61]$. These data suggest that combination therapies may be needed to improve GSI efficacy and improve the treatment of T-ALL patients. Using a high-throughput drug screening approach, Roti et al. [62] identified the sarco/endoplasmic reticulum calcium ATPase (SERCA) channels as targets in Notch1-driven T-ALL. Indeed, a small molecule SERCA inhibitor thapsigargin selectively interfered with Notch signaling and proved to have anti-leukemic activity in both in vitro and in vivo models.

The treatment with the mTOR inhibitor rapamycin increases the response to the chemotherapeutic agent dexamethasone in T-ALL cells [63]. Similarly, the dual PI3K/mTOR inhibitor NVP-BEZ235 induced apoptosis and showed strong synergic activity when administered with conventional chemotherapeutic agents in T-ALL cell lines and in primary patients lymphoblasts [64]. Since JAK/STAT pathway deregulation was found to be a key hallmark of immature leukemias harboring IL7R, JAK1, JAK3 or STAT5 alterations, specific small molecule inhibitors represent appealing agents for the treatment of this subset of T-ALL. Notably, the in vivo treatment with the JAK1/2 inhibitor ruxolitinib showed strong antitumoral effects in ETP- ALL patient-derived xenografts[65]. ETP-ALL is bcl-2 dependent and is very sensitive to in vitro and in vivo treatment with ABT-199, a drug well tolerated in clinical trials [66]. It is important to note that bcl-2 is highly expressed in early T-cell precursors and gradually decreases during normal T-cell differentiation. The response to ABT-199 has also proven effective in preclinical xenograft models of immature T-ALL and its combination with conventional chemotherapy displayed higher synergism providing a rationale for including this compound in clinical arenas [67]. Various small inhibitors as well as blocking antibodies against Wnt ligands or receptors have been synthesized and tested with promising anti-tumor activity [68-70].

Considering the fact that leukemic cells within maladapted niches can effectively evade therapy, treatments designed to de-bulk leukemic cells are likely to fail to eradicate cancer cells. Thus, it is anticipated that combination strategies targeting both intrinsic and extrinsic mechanisms will be necessary. Nevertheless, the disruption of the prosurvival signals from the host remains highly challenging. Currently, a variety of approaches have been tested, often designed to disrupt selfrenewal pathways induced by stromal cells. Drugs against cytokines and chemokines driving the leukemic cells, as well as adhesion molecules and growth factors controlling tumor-cell interactions represent valuable approaches to break the connection between T-ALL cells and stromal/host cells. In particular, in acute myeloid leukemia, most of the progresses have been achieved by development of CXCR4 inhibitors [71]. As discussed, these compounds can be used to disrupt the pro-survival pathways activated by CXCL12/CXCR4 axis, blocking downstream targets that include PI3K/Akt signals. This hypothesis is supported by prolonged remission of leukemic CXCR4-mice [6]. Furthermore, treatment with a CXCR4 antagonist (AMD3465) dramatically suppresses human T-ALL and prolongs the survival of xenograft mouse models. Toward this end, Passaro et al. [5] have also 
demonstrated that the transduction of human T-ALL with shCXCR4 vectors negatively affects the ability of T-ALL cells to migrate into the bone marrow spaces and slows disease initiation. This strongly supports the clinical potential for CXCR4 inhibition in the treatment of T-ALL. Meanwhile, CXCR4 inhibitors activate and mobilize leukemic cells out of niches to the peripheral blood where they are susceptible to co-administrated chemotherapy [6,16]. Thus, different studies are currently investigating the combination of chemotherapy with CXCR4 antagonist for the treatment of hematological malignancies, including ALL [72].

Additional strategies focus on blocking growth factor signaling pathways, via either inhibitors that directly target growth factor receptors on the surface of T-ALL cells or molecules that compete with their ligands provided by stromal cells. Of note, the inhibition of IGF1R, using both specific inhibitors and siRNA, resulted in a relevant reduction in T-ALL survival and proliferation. On the same line, Cao et al. [73] have recently shown that angiomodulin effectively inhibits the IGFR-1 receptor on tumor cells and delays the growth of cancer cells, suggesting its putative usage in the treatment of hematological disorders and many other human neoplasms addicted to IGF-1 signaling. In the case of T-ALL, the aberrant activation of Notch signaling enhances the expression of IGF1R signaling, making them highly responsive to IGF-1 provided by microenvironment [74]. Using specific inhibitors or genetic deletion of IGF1R, Medyouf et al. showed a significant reduction in the growth and viability of T-ALL cells in vitro and in a compromised tumor-initiating activity in transplanted mice.

In both normal and malignant BM microenvironment, restricted oxygen conditions regulate the self-renewal capacity and differentiation of stem cell subsets through the transcriptional activity of hypoxia inducible factors. In this contest, novel HIF-1 $\alpha$ inhibitors, capable of blocking HIF-1a DNA binding or disrupting its interaction with transcriptional co-activators have moved into the clinical arenas [75,76]. As HIF- $1 \alpha$ interacts with the chaperone HSP90, heat shock inhibitors can effectively induce HIF-1 $\alpha$ degradation [77]. Similarly, the topoisomerase I inhibitors were shown to reduce HIF-1a expression with consequent inhibition of angiogenesis and tumor growth in xenograft models[78]. These studies are also in line with findings observed in a mouse model of bcr-abl positive chronic myeloid leukemia in which the HIF1-a deletion was associated with reduced tumor initiation in secondary transplanted mice [79].

\section{Conclusions}

Despite improvements, substantial efforts are required to improve the understanding of the molecular and biological mechanisms dictating the mutual dependency of leukemic cells with their surrounding microenvironment. This is will eventually open new avenues to test and validate more effective strategies targeting both compartments and hopefully improve the outcome of leukemic patients.

\section{Financial support}

This work was partially supported by funds from the Leukemia Lymphoma Society, (SCOR grant) to G.I. and the AIRC 5xMille (Genetics-driven targeted management of lymphoid malignancies) to G.I.

\section{References}

1. Van Vlierberghe P, Ferrando A (2012) The molecular basis of T cell acute lymphoblastic leukemia. J Clin Invest 122: 3398-3406. [Crossref]
2. Durinck K, Goossens S, Peirs S, Wallaert A, Van Loocke W, et al. (2015) Novel biological insights in T-cell acute lymphoblastic leukemia. Exp Hematol 43: 625-639. [Crossref]

3. Ferrando AA, Neuberg DS, Staunton J, Loh ML, Huard C, et al. (2002) Gene expression signatures define novel oncogenic pathways in $\mathrm{T}$ cell acute lymphoblastic leukemia. Cancer Cell 1: 75-87. [Crossref]

4. Gianfelici V, Chiaretti S, Demeyer S, Di Giacomo F, Messina M, et al. (2016) RNA sequencing unravels the genetics of refractory/relapsed T-cell acute lymphoblastic leukemia. Prognostic and therapeutic implications. Haematologica 101: 941-950. [Crossref]

5. Passaro D, Irigoyen $\mathrm{M}$, Catherinet $\mathrm{C}$, Gachet $\mathrm{S}$, Da Costa De Jesus $\mathrm{C}$, et al (2015) CXCR4 Is Required for Leukemia-Initiating Cell Activity in T Cell Acute Lymphoblastic Leukemia. Cancer Cell 27: 769-779. [Crossref]

6. Pitt LA, Tikhonova AN, Hu H, Trimarchi T, King B, et al. (2015) CXCL12-Producing Vascular Endothelial Niches Control Acute T Cell Leukemia Maintenance. Cancer Cell 27: 755-768. [Crossref]

7. Belmonte M, Hoofd C, Weng AP, Giambra V (2016) Targeting leukemia stem cells which pathways drive self-renewal activity in T-cell acute lymphoblastic leukemia? Curr Oncol 23: 34-41. [Crossref]

8. Essers MA, Trumpp A (2010) Targeting leukemic stem cells by breaking their dormancy. Mol Oncol 4: 443-450. [Crossref]

9. Warner JK, Wang JC, Hope KJ, Jin L, Dick JE (2004) Concepts of human leukemic development. Oncogene 23: 7164-7177. [Crossref]

10. Wang JC, Dick JE (2005) Cancer stem cells: lessons from leukemia. Trends Cell Biol 15: 494-501. [Crossref]

11. Johnsen HE, Kjeldsen MK, Urup T, Fogd K, Pilgaard L, et al. (2009) Cancer stem cells and the cellular hierarchy in haematological malignancies. Eur J Cancer 45 Suppl 1 : 194-201. [Crossref]

12. Perry JM, Li L (2007) Disrupting the stem cell niche: good seeds in bad soil. Cell 129: 1045-1047.

13. Calvi LM, Adams GB, Weibrecht KW, Weber JM, Olson DP, et al. (2003) Osteoblastic cells regulate the haematopoietic stem cell niche. Nature 425: 841-846. [Crossref]

14. Kiel MJ, Yilmaz OH, Iwashita T, Yilmaz OH, Terhorst C, et al. (2005) SLAM family receptors distinguish hematopoietic stem and progenitor cells and reveal endothelial niches for stem cells. Cell 121: 1109-1121.

15. Zhang J, Niu C, Ye L, Huang H, He X, et al. (2003) Identification of the haematopoietic stem cell niche and control of the niche size. Nature 425: 836-841. [Crossref]

16. Trumpp A, Essers M, Wilson A (2010) Awakening dormant haematopoietic stem cells Nat Rev Immunol 10: 201-209. [Crossref]

17. Chiarini F, Lonetti A, Evangelisti C, Buontempo F, Orsini E, et al. (2016) Advances in understanding the acute lymphoblastic leukemia bone marrow microenvironment: From biology to therapeutic targeting. Biochim Biophys Acta 1863: 449-463. [crosssref]

18. Shiozawa Y, Havens AM, Pienta KJ, Taichman RS (2008) The bone marrow niche: habitat to hematopoietic and mesenchymal stem cells, and unwitting host to molecular parasites. Leukemia 22: 941-950. [Crossref]

19. Arai F, Hirao A, Ohmura M, Sato H, Matsuoka S, et al. (2004) Tie2/angiopoietin-1 signaling regulates hematopoietic stem cell quiescence in the bone marrow niche. Cell 118: 149-161. [Crossref]

20. Nilsson SK, Johnston HM, Whitty GA, Williams B, Webb RJ, et al. (2005) Osteopontin, a key component of the hematopoietic stem cell niche and regulator of primitive hematopoietic progenitor cells. Blood 106: 1232-1239. [Crossref]

21. Stier S, Ko Y, Forkert R, Lutz C, Neuhaus T, et al. (2005) Osteopontin is a hematopoietic stem cell niche component that negatively regulates stem cell pool size. J Exp Med 201: 1781-1791. [Crossref]

22. Wilson A, Murphy MJ, Oskarsson T, Kaloulis K, Bettess MD, et al. (2004) c-Myc controls the balance between hematopoietic stem cell self-renewal and differentiation. Genes Dev 18: 2747-2763. [Crossref]

23. Yamazaki S, Ema H, Karlsson G, Yamaguchi T, Miyoshi H, et al. (2011) Nonmyelinating Schwann cells maintain hematopoietic stem cell hibernation in the bone marrow niche. Cell 147: 1146-1158. [Crossref]

24. Kopp HG, Avecilla ST, Hooper AT, Rafii S (2005) The bone marrow vascular niche: home of HSC differentiation and mobilization. Physiology (Bethesda) 20: 349-356. [Crossref] 
25. Sugiyama T, Kohara H, Noda M, Nagasawa T (2006) Maintenance of the hematopoietic stem cell pool by CXCL12-CXCR4 chemokine signaling in bone marrow stromal cell niches. Immunity 25: 977-988. [Crossref]

26. Peled A, Kollet O, Ponomaryov T, Petit I, Franitza S, et al. (2000) The chemokine SDF-1 activates the integrins LFA-1, VLA-4, and VLA-5 on immature human CD34(+) cells: role in transendothelial/stromal migration and engraftment of NOD/SCID mice. Blood 95: 3289-3296. [Crossref]

27. Kucia M, Reca R, Miekus K, Wanzeck J, Wojakowski W, et al. (2005) Trafficking of normal stem cells and metastasis of cancer stem cells involve similar mechanisms: pivotal role of the SDF-1-CXCR4 axis. Stem Cells 23: 879-894. [Crossref]

28. Wilson A, Laurenti E, Oser G, van der Wath RC, Blanco-Bose W, et al. (2008) Hematopoietic stem cells reversibly switch from dormancy to self-renewal during homeostasis and repair. Cell 135: 1118-1129. [Crossref]

29. Heissig B, Hattori K, Dias S, Friedrich M, Ferris B, et al. (2002) Recruitment of stem and progenitor cells from the bone marrow niche requires MMP-9 mediated release of kit-ligand. Cell 109: 625-637. [Crossref]

30. Dührsen U, Hossfeld DK (1996) Stromal abnormalities in neoplastic bone marrow diseases. Ann Hematol 73: 53-70. [Crossref]

31. Raaijmakers MH, Mukherjee S, Guo S, Zhang S, Kobayashi T, et al. (2010) Bone progenitor dysfunction induces myelodysplasia and secondary leukaemia. Nature 464: 852-857. [Crossref]

32. Wang W, Zimmerman G, Huang X, Yu S, Myers J, et al. (2016) Aberrant Notch Signaling in the Bone Marrow Microenvironment of Acute Lymphoid Leukemia Suppresses Osteoblast-Mediated Support of Hematopoietic Niche Function. Cancer Res 76: 1641-1652. [Crossref]

33. Enciso J, Mayani H, Mendoza L, Pelayo R (2016) Modeling the Pro-inflammatory Tumor Microenvironment in Acute Lymphoblastic Leukemia Predicts a Breakdown of Hematopoietic-Mesenchymal Communication Networks. Front Physiol 7: 349. [Crossref]

34. Wang L, Fortney JE, Gibson LF (2004) Stromal cell protection of B-lineage acute lymphoblastic leukemic cells during chemotherapy requires active Akt. Leuk Res 28: 733-742.

35. Jiffar T, Kurinna S, Suck G, Carlson-Bremer D, Ricciardi MR, et al. (2004) PKC alpha mediates chemoresistance in acute lymphoblastic leukemia through effects on Bcl2 phosphorylation. Leukemia 18: 505-512. [Crossref]

36. Sipkins DA, Wei X, Wu JW, Runnels JM, Cote D, et al. (2005) In vivo imaging of specialized bone marrow endothelial microdomains for tumour engraftment. Nature 435: 969-973. [Crossref]

37. Kebelmann-Betzing C, Korner G, Badiali L, Buchwald D, Moricke A, et al. (2001) Characterization of cytokine, growth factor receptor, costimulatory and adhesion molecule expression patterns of bone marrow blasts in relapsed childhood B cell precursor all. Cytokine 13: 39-50.

38. Uzan B, Poglio S, Gerby B, Wu CL, Gross J, et al. (2014) Interleukin-18 produced by bone marrow-derived stromal cells supports T-cell acute leukaemia progression. EMBO Mol Med 6: 821-834. [Crossref]

39. Scupoli MT, Donadelli M, Cioffi F, Rossi M, Perbellini O, et al. (2008) Bone marrow stromal cells and the upregulation of interleukin- 8 production in human T-cell acute lymphoblastic leukemia through the CXCL12/CXCR4 axis and the NF-kappaB and JNK/AP-1 pathways. Haematologica 93: 524-532. [Crossref]

40. Chiaretti S, Li X, Gentleman R, Vitale A, Vignetti M, et al. (2004) Gene expression profile of adult T-cell acute lymphocytic leukemia identifies distinct subsets of patients with different response to therapy and survival. Blood 103: 2771-2778.

41. Espinoza-Hernandez L, Cruz-Rico J, Benitez-Aranda H, Martinez-Jaramillo G, Rodriguez-Zepeda MC, et al. (2001) In vitro characterization of the hematopoietic system in pediatric patients with acute lymphoblastic leukemia. Leuk Res 25: 295-303. [Crossref]

42. Triplett TA, Cardenas KT, Lancaster JN, Hu Z, Selden HJ, et al. (2016) Endogenous dendritic cells from the tumor microenvironment support T-ALL growth via IGF1R activation. Proc Natl Acad Sci 113: E1016-1025.

43. Indraccolo S, Minuzzo S, Masiero M, Pusceddu I, Persano L, et al. (2009) Cross-talk between tumor and endothelial cells involving the Notch3-D114 interaction marks escape from tumor dormancy. Cancer Res 69: 1314-1323. [Crossref]

44. Minuzzo S, Agnusdei V, Pusceddu I, Pinazza M, Moserle L, et al. (2015) DLL4 regulates NOTCH signaling and growth of $\mathrm{T}$ acute lymphoblastic leukemia cells in NOD/SCID mice. Carcinogenesis 36: 115-121. [Crossref]
45. Nwabo Kamdje AH, Mosna F, Bifari F, Lisi V, Bassi G, et al. (2011) Notch-3 and Notch-4 signaling rescue from apoptosis human B-ALL cells in contact with human bone marrow-derived mesenchymal stromal cells. Blood 118: 380-389. [Crossref]

46. Winter SS, Sweatman JJ, Lawrence MB, Rhoades TH, Hart AL, et al. (2001) Enhanced T-lineage acute lymphoblastic leukaemia cell survival on bone marrow stroma requires involvement of LFA-1 and ICAM-1. Br J Haematol 115: 862-871. [Crossref]

47. Shalapour S, Hof J, Kirschner-Schwabe R, Bastian L, Eckert C, et al. (2011) High VLA-4 expression is associated with adverse outcome and distinct gene expression changes in childhood B-cell precursor acute lymphoblastic leukemia at first relapse. Haematologica 96: 1627-1635. [Crossref]

48. Jacamo R, Chen Y, Wang Z, Ma W, Zhang M, et al. (2014) Reciprocal leukemia-stroma VCAM-1/VLA-4-dependent activation of NF-kappaB mediates chemoresistance. Blood 123: 2691-2702. [Crossref]

49. Weng AP, Millholland JM, Yashiro-Ohtani Y, Arcangeli ML, Lau A, et al. (2006) c-Myc is an important direct target of Notch1 in T-cell acute lymphoblastic leukemia/ lymphoma. Genes Dev 20: 2096-2109. [Crossref]

50. Armstrong F, Brunet de la Grange P, Gerby B, Rouyez MC, Calvo J, et al. (2009) NOTCH is a key regulator of human T-cell acute leukemia initiating cell activity. Blood 113: 1730-1740. [Crossref]

51. Tatarek J, Cullion K, Ashworth T, Gerstein R, Aster JC, et al. (2011) Notch1 inhibition targets the leukemia-initiating cells in a Tal1/Lmo2 mouse model of T-ALL. Blood 118: 1579-1590. [Crossref]

52. Hales EC, Taub JW, Matherly LH (2014) New insights into Notch1 regulation of the PI3K-AKT-mTOR1 signaling axis: targeted therapy of gamma-secretase inhibitor resistant T-cell acute lymphoblastic leukemia. Cell Signal 26: 149-161. [Crossref]

53. Takubo K, Goda N, Yamada W, Iriuchishima H, Ikeda E, et al. (2010) Regulation of the HIF-1alpha level is essential for hematopoietic stem cells. Cell Stem Cell 7: 391-402. [Crossref]

54. Wang Y, Liu Y, Malek SN, Zheng P, Liu Y (2011) Targeting HIF1 ̂̂̀ eliminates cancer stem cells in hematological malignancies. Cell Stem Cell 8: 399-411. [Crossref]

55. Gezer D, Vukovic M, Soga T, Pollard PJ, Kranc KR (2014) Concise review: genetic dissection of hypoxia signaling pathways in normal and leukemic stem cells. Stem Cells 32: 1390-1397. [Crossref]

56. Giambra V, Jenkins CE1, Lam SH1, Hoofd C, Belmonte M, et al. (2015) Leukemia stem cells in T-ALL require active Hif1 $1 \mathrm{I} \pm$ and Wnt signaling. Blood 125: 3917-3927. [Crossref]

57. Papayannidis C, DeAngelo DJ, Stock W, Huang B, Shaik MN, et al. (2015) A Phase 1 study of the novel gamma-secretase inhibitor PF-03084014 in patients with T-cell acute lymphoblastic leukemia and T-cell lymphoblastic lymphoma. Blood Cancer J 5: e350. [Crossref]

58. Knoechel B, Bhatt A, Pan L, Pedamallu CS, Severson E, et al. (2015) Complete hematologic response of early T-cell progenitor acute lymphoblastic leukemia to the gamma-secretase inhibitor BMS-906024: genetic and epigenetic findings in an outlier case. Cold Spring Harb Mol Case Stud 1: a000539. [Crossref]

59. Cullion K, Draheim KM, Hermance N, Tammam J, Sharma VM, et al. (2009) Targeting the Notch1 and mTOR pathways in a mouse T-ALL model. Blood 113: 6172-6181. [Crossref]

60. Chan SM, Weng AP, Tibshirani R, Aster JC, Utz PJ (2007) Notch signals positively regulate activity of the mTOR pathway in T-cell acute lymphoblastic leukemia. Blood 110: 278-286. [Crossref]

61. Shepherd C, Banerjee L, Cheung CW, Mansour MR, Jenkinson S, et al. (2013) $\mathrm{PI} 3 \mathrm{~K} / \mathrm{mTOR}$ inhibition upregulates NOTCH-MYC signalling leading to an impaired cytotoxic response. Leukemia 27: 650-660. [Crossref]

62. Roti G, Carlton A, Ross KN, Markstein M, Pajcini K, et al. (2013) Complementary genomic screens identify SERCA as a therapeutic target in NOTCH1 mutated cancer. Cancer Cell 23: 390-405. [Crossref]

63. Zhang C, Ryu YK, Chen TZ, Hall CP, Webster DR, et al. (2012) Synergistic activity of rapamycin and dexamethasone in vitro and in vivo in acute lymphoblastic leukemia via cell-cycle arrest and apoptosis. Leuk Res 36: 342-349. [Crossref]

64. Chiarini F, Grimaldi C, Ricci F, Tazzari PL, Evangelisti C, et al. (2010) Activity of the novel dual phosphatidylinositol 3-kinase/mammalian target of rapamycin inhibitor NVP-BEZ235 against T-cell acute lymphoblastic leukemia. Cancer Res 70: 8097-8107. [Crossref]

65. Maude SL, Dolai S, Delgado-Martin C, Vincent T, Robbins A, et al. (2015) Efficacy 
of JAK/STAT pathway inhibition in murine xenograft models of early T-cell precursor (ETP) acute lymphoblastic leukemia. Blood 125: 1759-1767. [Crossref]

66. Chonghaile TN, Roderick JE, Glenfield C, Ryan J, Sallan SE, et al. (2014) Maturation stage of T-cell acute lymphoblastic leukemia determines BCL-2 versus BCL-XL dependence and sensitivity to ABT-199. Cancer Discov 4: 1074-1087. [Crossref]

67. Peirs S, Matthijssens F, Goossens S, Van de Walle I, et al. (2014) ABT-199 mediated inhibition of BCL-2 as a novel therapeutic strategy in T-cell acute lymphoblastic leukemia. Blood 124: 3738-3747.

68. Thorne CA, Hanson AJ, Schneider J, Tahinci E, Orton D, et al. (2010) Small-molecule inhibition of Wnt signaling through activation of casein kinase 1alpha. Nat Chem Biol 6: 829-836. [Crossref]

69. Huang SM, Mishina YM, Liu S, Cheung A, Stegmeier F, et al. (2009) Tankyrase inhibition stabilizes axin and antagonizes Wnt signalling. Nature 461: 614-620. [Crossref]

70. Chen B, Dodge ME, Tang W, Lu J, Ma Z, et al. (2009) Small molecule-mediated disruption of Wnt-dependent signaling in tissue regeneration and cancer. Nat Chem Biol 5: 100-107. [Crossref]

71. Rashidi A, DiPersio JF2 (2016) Targeting the leukemia-stroma interaction in acute myeloid leukemia: rationale and latest evidence. Ther Adv Hematol 7: 40-51. [Crossref]

72. Burger JA, Kipps TJ (2006) CXCR4: a key receptor in the crosstalk between tumor cells and their microenvironment. Blood 107: 1761-1767. [Crossref]
73. Cao Z, Ding BS, Guo P, Lee SB, Butler JM, et al. (2014) Angiocrine factors deployed by tumor vascular niche induce B cell lymphoma invasiveness and chemoresistance. Cancer Cell 25: 350-365. [Crossref]

74. Medyouf H, Gusscott S, Wang H, Tseng JC, Wai C, et al. (2011) High-level IGF1R expression is require for leukemia-initiating cell activity in T-ALL and is supported by Notch signaling. $J$ Exp Med 208: 1809-1822. [Crossref]

75. Kong D, Park EJ, Stephen AG, Calvani M, Cardellina JH, et al. (2005) Echinomycin, a small-molecule inhibitor of hypoxia-inducible factor-1 DNA-binding activity. Cancer Res 65: 9047-9055. [Crossref]

76. Kung AL, Zabludoff SD, France DS, Freedman SJ, Tanner EA, et al. (2004) Small molecule blockade of transcriptional coactivation of the hypoxia-inducible factor pathway. Cancer Cell 6: 33-43. [Crossref]

77. Isaacs JS, Jung YJ, Mimnaugh EG, Martinez A, Cuttitta F, et al. (2002) Hsp90 regulates a von Hippel Lindau-independent hypoxia-inducible factor-1 alpha-degradative pathway. J Biol Chem 277: 29936-29944. [Crossref]

78. Guerin E, Raffelsberger W, Pencreach E, Maier A, Neuville A, et al. (2012) In vivo topoisomerase I inhibition attenuates the expression of hypoxia-inducible factor 1alpha target genes and decreases tumor angiogenesis. Mol Med 18: 83-94. [Crossref]

79. Zhang H, Li H, Xi HS, Li S (2012) HIF1 $1 \mathrm{I} \pm$ is required for survival maintenance of chronic myeloid leukemia stem cells. Blood 119: 2595-2607. [Crossref]

Copyright: $\odot 2017$ Giacomo FD. This is an open-access article distributed under the terms of the Creative Commons Attribution License, which permits unrestricted use, distribution, and reproduction in any medium, provided the original author and source are credited. 